\title{
Production of High-Purity Indium and Gallium Metals by Vacuum Refining
}

\author{
Man-Seung Lee ${ }^{1}$, Jong-Gwan $\mathrm{Ahn}^{2}$ and Young-Joo $\mathrm{Oh}^{3}$ \\ ${ }^{1}$ Department of Advanced Materials Science \& Engineering, Mokpo National University, Chonnam 534-729, Korea \\ ${ }^{2}$ Minerals and Materials Processing Division, Korea Institute of Geoscience and Mineral Resources, Daejoen 305-3, Korea \\ ${ }^{3}$ Metal Processing Research Center, Korea Institute of Science and Technology, P.O. Box 131, Cheongryang, Seoul, Korea
}

Vacuum refining experiments of indium and gallium metals have been performed. When indium metal of $99.97 \%$ purity was refined at $1273 \mathrm{~K}$ and $1.3 \times 10^{-3} \mathrm{~Pa}$ for one hour, $\mathrm{Pb}$ and $\mathrm{Bi}$ were effectively removed from indium metal. After refining $99.9 \% \mathrm{Ga}$ at $1373 \mathrm{~K}$ and $1.3 \times 10^{-3} \mathrm{~Pa}$ for six hours, removal of $\mathrm{Bi}, \mathrm{Pb}, \mathrm{Zn}, \mathrm{Mg}, \mathrm{Ca}$ and Fe were confirmed. The difference of temperature between indium and gallium at which the recovery percentage was abruptly decreased was related to the difference of boiling temperatures of both metals at the pressure of $1.3 \times 10^{-3} \mathrm{~Pa}$. The vaporization rate of solvent metals obtained from experiments were compared with those calculated by Langmuir equation.

(Received April 22, 2002; Accepted October 1, 2002)

Keywords: indium, gallium; vacuum refining

\section{Introduction}

Indium and gallium metals with purity levels of six nine $(99.9999 \%)$ are needed in the preparation of the compound for semiconductor applications. Methods for the purification of indium and gallium such as vacuum refining, electrolysis, zone refining and recrystallization have been studied. ${ }^{1-6)}$

Both indium and gallium metals have low melting points and high boiling points. Therefore, it is possible to remove the impurity metals with high vapor pressure by vaporization of these metals at relatively low temperature. Vacuum refining is a physical process in which the difference of vapor pressure between impurity metals and solvent metal is utilized to remove the impurity metals by evaporating the impurity metals under vacuum. Since the impurity metals, which are not well removed by chemical method, are easily removed by vacuum refining at relatively low temperatures, purification of metals by vacuum refining is widely practiced.

In this study, the effects of temperature and time on the vacuum refining of indium and gallium metals have been investigated. From the experimental results, optimum conditions to purify indium and gallium were obtained.

\section{Experimental}

The indium and gallium metal (Aldrich Chemical Co., purity of $99.97 \%$ and $99.9 \%$, respectively) were used as raw materials for vacuum refining. The chemical compositions of both metals are shown in Tables 1 and 2 .

The schematic diagram of experimental apparatus is shown in Fig. 1. The raw material of $8.3 \mathrm{~g}$ was put in a quartz boat (volume $1.1 \times 10^{-5} \mathrm{~m}^{3}$ ). The surface area of molten metal in the boat, which was exposed to the vapor phase, was determined as $1 \times 10^{-3} \mathrm{~m}^{2}$ from the dimension of the quartz boat. This boat was then placed in the quartz tube, the one end of which was sealed. This quartz tube was loaded in the horizontal electric tube furnace. The quartz tube was evacuated by means of a diffusion pump. The vacuum pressure was measured by Penning vacuum gauge. Once the desired temperature was reached, the temperature was maintained for
Table 1 Chemical composition of indium crude metal (mass ppm).

\begin{tabular}{ccccccc}
\hline $\mathrm{Al}$ & $\mathrm{Mg}$ & $\mathrm{Cu}$ & $\mathrm{Cd}$ & $\mathrm{Sn}$ & $\mathrm{Pb}$ & $\mathrm{Bi}$ \\
\hline 2 & 0.1 & 1.7 & 0.5 & 5 & 30 & 61 \\
\hline
\end{tabular}

Table 2 Chemical composition of gallium crude metal (mass ppm).

\begin{tabular}{lccccccc}
\hline $\mathrm{Bi}$ & $\mathrm{Fe}$ & $\mathrm{Mg}$ & $\mathrm{Pb}$ & $\mathrm{Cu}$ & $\mathrm{Zn}$ & $\mathrm{Ca}$ \\
\hline 30 & 20 & 3 & 80 & 12 & 29 & 14 \\
\hline
\end{tabular}

Fig. 1 Schematic diagram of experimental apparatus.

certain time and after finishing experiments the samples were subjected to the analysis.

After dissolving both metals in hydrochloric acid solutions, impurity concentrations were measured with A.A. (PerkinElmer, Model No. 3030B) and I.C.P. (Thermo Jarren Ash, Model No. Polyscan 61E). The detection limits of impurity metals were as follows; for $\mathrm{Bi}<0.1 \mathrm{ppm}$, for $\mathrm{Mg}<$ $0.01 \mathrm{ppm}$, for $\mathrm{Pb}<0.5 \mathrm{ppm}$ and for $\mathrm{Zn}<0.1 \mathrm{ppm}$. The mass change of indium and gallium metal was measured by mass balance (Mettler Model No. AE 160).

\section{Results and Discussion}

At the vacuum pressure of $1.3 \times 10^{-3} \mathrm{~Pa}$, indium metals were refined in the temperatures from $923 \mathrm{~K}$ to $1323 \mathrm{~K}$ for two hours. At the same vacuum pressure, gallium metals were 


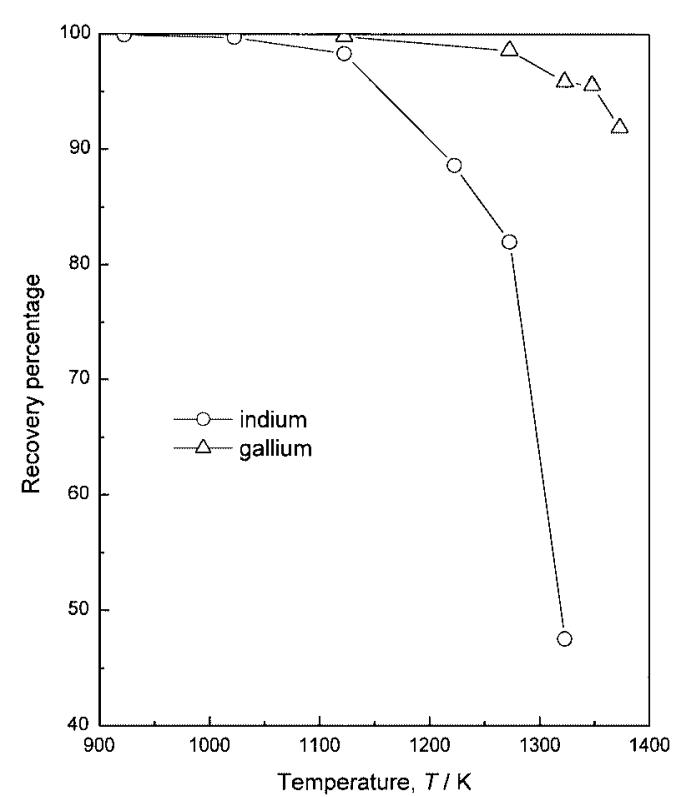

Fig. 2 Effect of temperature on the recovery percentage of indium and gallium. $\left(P=1.3 \times 10^{-3} \mathrm{~Pa}\right.$, Time $\left.=2 \mathrm{~h}\right)$.

also treated in the temperatures from 1123 to $1373 \mathrm{~K}$ for two hours. The effects of refining temperature on the recovery of both metals are shown in Fig. 2. Although the recovery percentage of indium metal gradually decreased from 923 to $1123 \mathrm{~K}$, it abruptly decreased to $50 \%$ at $1323 \mathrm{~K}$. It is shown in Fig. 2 that the recovery percentage of gallium also decreased with the increase of temperature but is above $90 \%$ in the experimental range of the present study.

It is found from Fig. 2 that the temperature at which the recovery percentage drops suddenly for gallium metal is $150 \mathrm{~K}$ higher than that for indium metal. This temperature difference is similar to the boiling temperature difference between two metals. The boiling point of indium is $2335 \mathrm{~K}$ and that of gallium is $2693 \mathrm{~K}$ at the pressure of $1.013 \times 10^{5} \mathrm{~Pa}$. ${ }^{7}$ The heats of vaporization of indium and gallium are $231.8 \mathrm{~kJ} / \mathrm{mol}$ and $270.3 \mathrm{~kJ} / \mathrm{mol}$, respectively. ${ }^{7)}$ By inserting the above physical values of both metals into Clausius-Clapeyron equation, the boiling points of indium and gallium are calculated as $926 \mathrm{~K}$ and $1075 \mathrm{~K}$, respectively, at the pressure of $1.3 \times 10^{-3} \mathrm{~Pa}$.

The effects of temperature on the vaporization rate of indium and gallium at the pressure of $1.3 \times 10^{-3} \mathrm{~Pa}$ were investigated by varying refining time. The variation of mass change $(\Delta W)$ of indium and gallium with refining time at various temperatures are shown in Figs. 3 and 4, respectively. From Figs. 3 and 4, it is known that the mass change of indium and gallium increases with refining time and the rate of mass change of both metals increases with temperature.

The maximum rate of vaporization at low pressure (Langmuir equation) is given by eq. (1) and is applied to the vaporization at low pressure when no energy of activation is required. ${ }^{8)}$

$$
\text { Rate }_{\max }=\frac{P_{\mathrm{i}}}{\sqrt{2 \pi M_{\mathrm{i}} R T}}
$$

In the above equation, $P_{\mathrm{i}}$ represents the vapor pressure and $M_{\mathrm{i}}$ the molecular weight of the vaporizing species and $T$ the reaction temperature. Inserting the appropriate units in the

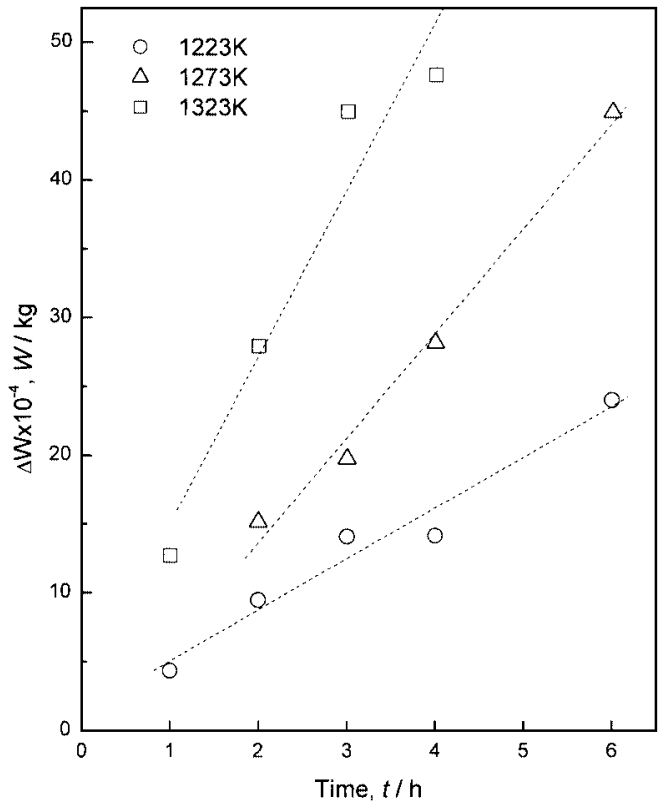

Fig. 3 Effect of temperature and time on the mass change of indium. $\left(P=1.3 \times 10^{-3} \mathrm{~Pa}\right)$.

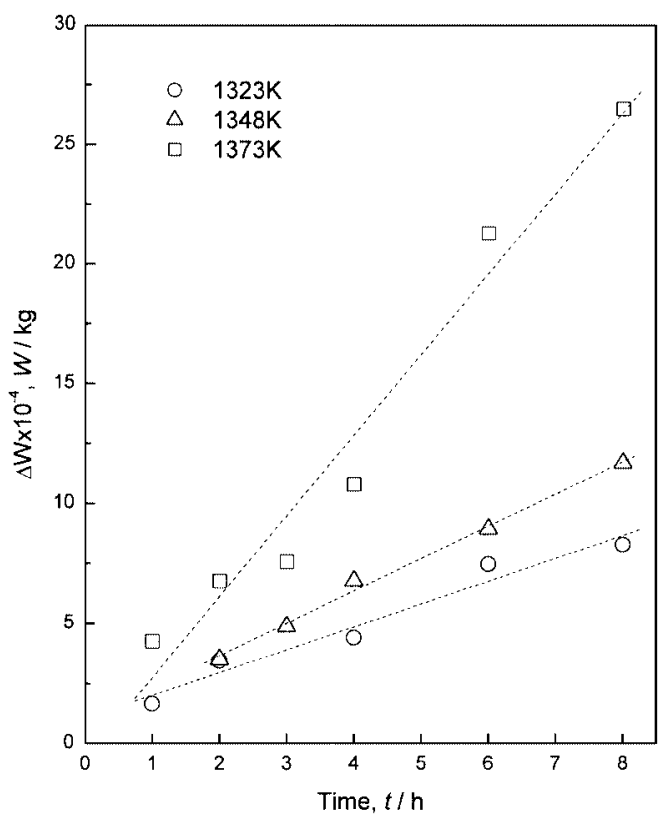

Fig. 4 Effect of temperature and time on the mass change of gallium. $\left(P=1.3 \times 10^{-3} \mathrm{~Pa}\right)$.

above equation gives

$$
\text { Rate }_{\max }=44.3 \frac{P_{\mathrm{i}}}{\sqrt{M_{\mathrm{i}} T}}\left(\frac{\text { mole }}{\mathrm{cm}^{2} \times \mathrm{s}}\right)
$$

In eq. (2), the unit of vapor pressure is atmosphere and the unit of molecular weight is $\mathrm{g} / \mathrm{mol}$.

Substituting both the molecular weight and the vapor pressure of metal at the temperature $T$ into eq. (2) gave the maximum rate of vaporization of metal. Multiplying the resulting equation by the surface area of molten metal $\left(1 \times 10^{-3} \mathrm{~m}^{2}\right)$ and converting the units of equation gave the maximum rate of mass change $(\mathrm{kg} / \mathrm{h})$ of solvent metal. The experimental mass change rates of both metals were obtained from the slopes of reaction time vs. mass change plot in Figs. 3 and 4. To com- 
pare the experimental mass change rates of both metals with the maximum rates of mass change of both metals, the results are represented together in Tables 3 and 4. From Tables 3 and 4 , it is known that the mass change rates obtained experimentally are much smaller than those calculated by eq. (2). The ratio of experimental mass change rate to the maximum rate of mass change of both metals is also represented in Tables 3 and 4. From Tables 3 and 4, it is seen that the ratio of mass change rate of indium is about 0.03 and that of gallium is from 0.06 to 0.1 in the experimental ranges. The difference between the experimentally obtained rate and the calculated rate may be related with the formation of oxide layer on the surface of metal.

The variation of the concentrations of the impurity metal in the indium with temperature and time are shown in Table 5. It is known from Table 5 that most of $\mathrm{Bi}$ and $\mathrm{Pb}$ metals, which are the major solutes of the indium metal, are easily removed by vacuum refining at $1273 \mathrm{~K}$ for one hour. The removal mass percentage of $\mathrm{Bi}$ and $\mathrm{Pb}$ from the indium metal was calculated

Table 3 Comparison of mass change rates of indium obtained experimentally and those calculated by Langmuir equation.

\begin{tabular}{crccc}
\hline $\begin{array}{c}\text { Temperature, } \\
T / \mathrm{K}\end{array}$ & $\begin{array}{c}P_{\text {In }}, \\
P / \mathrm{Pa}\end{array}$ & $\begin{array}{c}\text { Rate, } \\
R / \mathrm{kg} \cdot \mathrm{h}^{-1}\end{array}$ & $\begin{array}{c}\text { Rate } \\
R / \mathrm{kg} \cdot \mathrm{h}^{-1}\end{array}$ & $\begin{array}{c}\text { Ratio of mass } \\
\text { change rate }\end{array}$ \\
\hline 1223 & 1.95 & $3.7 \times 10^{-4}$ & $94.2 \times 10^{-4}$ & 0.04 \\
1273 & 4.78 & $7.6 \times 10^{-4}$ & $226.4 \times 10^{-4}$ & 0.03 \\
1323 & 10.94 & $12.2 \times 10^{-4}$ & $508.2 \times 10^{-4}$ & 0.02 \\
\hline
\end{tabular}

Table 4 Comparison of mass change rates of gallium obtained experimentally and those calculated by Langmuir equation.

\begin{tabular}{ccccc}
\hline $\begin{array}{c}\text { Temperature, } \\
T / \mathrm{K}\end{array}$ & $\begin{array}{c}P_{\mathrm{Ga}}, \\
P / \mathrm{Pa}\end{array}$ & $\begin{array}{c}\text { Rate, } \\
R / \mathrm{kg} \cdot \mathrm{h}^{-1}\end{array}$ & $\begin{array}{c}\text { Rate } \max , \\
R / \mathrm{kg} \cdot \mathrm{h}^{-1}\end{array}$ & $\begin{array}{c}\text { Ratio of mass } \\
\text { change rate }\end{array}$ \\
\hline 1323 & 0.38 & $0.95 \times 10^{-4}$ & $13.6 \times 10^{-4}$ & 0.07 \\
1348 & 0.60 & $1.35 \times 10^{-4}$ & $21.3 \times 10^{-4}$ & 0.06 \\
1373 & 0.92 & $3.37 \times 10^{-4}$ & $32.7 \times 10^{-4}$ & 0.10 \\
\hline
\end{tabular}

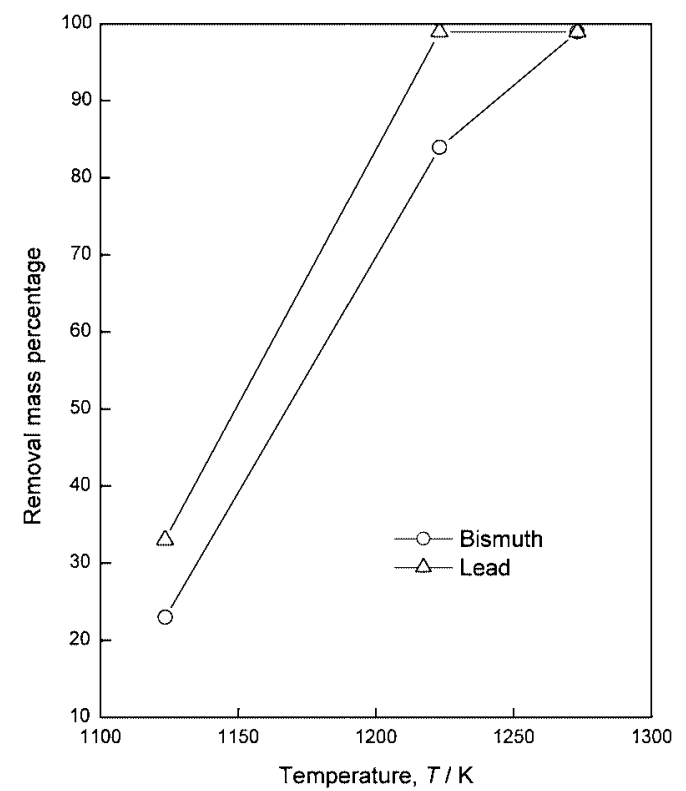

Fig. 5 Effect of temperature on the removal mass percentage of $\mathrm{Bi}$ and $\mathrm{Pb}$ from indium. (Time $=2 \mathrm{~h}$ ). by eq. (3) and the results are shown in Fig. 5.

$$
\text { Removal mass percentage }=\frac{W_{\mathrm{i}, \mathrm{o}}-W_{\mathrm{i}, \mathrm{T}}}{W_{\mathrm{i}, \mathrm{o}}} \times 100
$$

In the above equation, $W_{\mathrm{i}, \mathrm{o}}$ represents the initial mass of solutes in the indium metal and $W_{\mathrm{i}, \mathrm{T}}$ the mass of solutes after vacuum refining at temperature $T$ for two hours.

It is known from Fig. 5 and Table 5 that $33 \%$ of $\mathrm{Pb}$ and $23 \%$ of $\mathrm{Bi}$ are removed from the indium metal by vacuum refining at $1123 \mathrm{~K}$ for two hours. The removal mass percentage of $\mathrm{Bi}$ and $\mathrm{Pb}$ increased with the increase of temperature and $99 \%$ of $\mathrm{Bi}$ as well as $98 \%$ of $\mathrm{Pb}$ in the indium metal were removed at $1273 \mathrm{~K}$ for one hour. Among the impurity metals in the indium, it is difficult to remove $\mathrm{Al}, \mathrm{Sn}$ and $\mathrm{Cu}$ by vacuum refining because of the low vapor pressure of these metals. However, nearly almost of $\mathrm{Bi}, \mathrm{Pb}, \mathrm{Mg}$ and $\mathrm{Cd}$ were removed by vacuum refining at $1273 \mathrm{~K}$ for one hour because these metals have higher vapor pressure than indium.

The variation of the concentrations of the impurity in the gallium metal with vacuum refining conditions is shown in Table 6. It is known from Table 6 that nearly almost of the $\mathrm{Pb}$, $\mathrm{Bi}$ and $\mathrm{Zn}$ were removed from gallium by vacuum refining at $1323 \mathrm{~K}$ for two hours. And $82 \%$ of $\mathrm{Mg}$ and $79 \%$ of Ca were removed from gallium by vacuum refining at $1373 \mathrm{~K}$ for two hours. However, further increase of refining time at $1373 \mathrm{~K}$ had little effect on the removal of $\mathrm{Ca}$ and $\mathrm{Mg}$ from gallium by vacuum refining. In the case of vacuum refining of indium, $\mathrm{Mg}$ present in the indium metal was nearly removed under experimental conditions investigated in this work. Since $\mathrm{Ca}$ and $\mathrm{Mg}$ have higher vapor pressure than gallium, the fact that $\mathrm{Ca}$ and $\mathrm{Mg}$ were not nearly removed from gallium by vacuum refining suggests that some of $\mathrm{Ca}$ and $\mathrm{Mg}$ in the gallium might exist as oxide form.

It is shown in Table 6 that the concentration of Fe decreases

Table 5 Chemical composition of indium obtained from various experimental conditions (mass ppm).

\begin{tabular}{ccccc}
\hline $\begin{array}{c}\text { Experimental } \\
\text { conditions }\end{array}$ & $\mathrm{Mg}$ & $\mathrm{Cu}$ & $\mathrm{Pb}$ & $\mathrm{Bi}$ \\
\hline $\begin{array}{c}\text { Starting material } \\
1123 \mathrm{~K}, 2 \mathrm{~h}\end{array}$ & 0.1 & 1.7 & 30 & 61 \\
$1223 \mathrm{~K}, 2 \mathrm{~h}$ & $<0.01$ & 1.6 & 20 & 47 \\
$1273 \mathrm{~K}, 1 \mathrm{~h}$ & $<0.01$ & 2.0 & $<0.5$ & 10 \\
$1273 \mathrm{~K}, 2 \mathrm{~h}$ & $<0.01$ & 2.0 & $<0.5$ & $<0.1$ \\
$1273 \mathrm{~K}, 3 \mathrm{~h}$ & $<0.01$ & 2.6 & $<0.5$ & $<0.1$ \\
$1273 \mathrm{~K}, 4 \mathrm{~h}$ & $<0.01$ & 2.6 & $<0.5$ & $<0.1$ \\
$1273 \mathrm{~K}, 6 \mathrm{~h}$ & $<0.01$ & 2.6 & $<0.5$ & $<0.1$ \\
\hline
\end{tabular}

Table 6 Chemical composition of gallium obtained from various experimental conditions (mass ppm).

\begin{tabular}{clccccc}
\hline $\begin{array}{c}\text { Experimental } \\
\text { conditions }\end{array}$ & $\mathrm{Mg}$ & $\mathrm{Ca}$ & $\mathrm{Fe}$ & $\mathrm{Zn}$ & $\mathrm{Bi}$ & $\mathrm{Pb}$ \\
\hline $\begin{array}{c}\text { Starting material } \\
1323 \mathrm{~K}, 2 \mathrm{~h}\end{array}$ & 3 & 14 & 20 & 29 & 30 & 80 \\
$1373 \mathrm{~K}, 2 \mathrm{~h}$ & 0.34 & 2.9 & 15 & $<0.1$ & $<0.1$ & $<0.5$ \\
$1373 \mathrm{~K}, 4 \mathrm{~h}$ & 0.28 & 1.5 & 11 & $<0.1$ & $<0.1$ & $<0.5$ \\
$1373 \mathrm{~K}, 6 \mathrm{~h}$ & 0.32 & 2 & 5.7 & $<0.1$ & $<0.1$ & $<0.5$ \\
\hline
\end{tabular}


with the increase of reaction time at the temperature of $1373 \mathrm{~K}$ and $72 \%$ of $\mathrm{Fe}$ is removed by vacuum refining for six hours. Although the vapor pressure of $\mathrm{Fe}$ is lower than that of $\mathrm{Ga}$ at the same temperature, the concentration of Fe decreased with reaction time. The behavior of Fe during vacuum refining might be related to the thermodynamic behavior of $\mathrm{Fe}$ in $\mathrm{Ga}$. If $\mathrm{Ga}$ and $\mathrm{Fe}$ showed positive deviation from Raoultian behavior, the tendency of Fe to escape from Ga metal increased and the concentration of Fe decreased.

\section{Conclusions}

From the vacuum refining experiments of indium and gallium metal by varying temperature and time, the following conclusions were obtained.

(1) Nearly almost of the $\mathrm{Pb}$ and $\mathrm{Bi}$ were removed from indium by vacuum refining at $1273 \mathrm{~K}$ and $1.3 \times 10^{-3} \mathrm{~Pa}$ for one hour. Nearly almost of the $\mathrm{Bi}, \mathrm{Pb}, \mathrm{Zn}$ and $72 \%$ of $\mathrm{Fe}$ were removed from gallium by vacuum refining at $1373 \mathrm{~K}$ and $1.3 \times 10^{-3} \mathrm{~Pa}$ for six hours.

(2) The recovery percentage of indium and gallium metal decreased with the increase of temperature and time. The difference of temperature between indium and gallium at which the recovery percentage was abruptly decreased was equal to the difference of boiling temperatures of both metals at the pressure of $1.3 \times 10^{-3} \mathrm{~Pa}$.

\section{REFERENCES}

1) M. F. McNamara, J. A. Slattery and A. F. Witt: US Patent 4,828,608.

2) J. A. Adamski: US Patent 4,559,217.

3) R. B. Massy: US Patent 3,180,812.

4) S. L. Eriangen: US Patent 3,325,380.

5) A. B. I. Bollong and R. P. Bult: US Patent, 4,888,051.

6) J. G. Harper: US Patent, 3,088,853.

7) O. Kubaschewski and C. B. Alcock: Metallurgical thermochemistry, fifth ed., (Pergamon Press, Oxford, 1979) pp. 363-364.

8) E. T. Turkdogan: Physical chemistry of high temperature technology, (Academic Press INC., NY, 1980) p. 233. 